\title{
STUDI KASUS GANGGUAN MOBILITAS FISIK PASIEN STROKE ISKEMIK DENGAN HEMIPARESIS SETELAH DIBERIKAN STIMULASI SIKAT SENSORI
}

\author{
Sandra $^{1}$, Meisa Daniati ${ }^{2}$, Sopia Harni ${ }^{3}$ \\ ${ }^{1}$ Medical Surgical Nursing Department PSSK-STIKes Hang Tuah Pekanbaru, Indonesia \\ email: sandra@htp.ac.id \\ ${ }^{2}$ Medical Surgical Nursing Department PSSK-STIKes Hang Tuah Pekanbaru, Indonesia \\ email: ns.meisa1005@gmail.com \\ ${ }^{3}$ Arifin Achmad General Hospital Riau, Indonesia \\ email: sofiaharni79@gmail.com
}

\begin{abstract}
The role of nurses in nursing care, on the principle of rehabilitation of stroke patients with hemiparesis, is to move, help patients prevent contractures, and improve their motor function independently. The patient's independent movement exercises use the side of the limb that is not painful to help strengthen the weak muscles with various methods of stimulation, one of which is brushing. This study aims to determine the effect of using a sensory brush on limb muscle strength in ischemic stroke patients with hemiparesis. The research method is a case study using consecutive sampling. From the analysis, it was found that there was an effect of using a sensory brush on the increase in limb muscle strength in ischemic stroke patients. The conclusion obtained from this case study is the effect of using a sensory brush, which can be seen from the difference in limb muscle strength of stroke patients on a scale of 3 increasing on a scale of 4.
\end{abstract}

Keywords: Sensory Brush, Muscle Strength, Stroke

\section{Abstrak}

Peran perawat dalam asuhan keperawatan pada prinsip rehabilitasi pasien stroke yang mengalami hemiparesis adalah bergerak, membantu pasien mencegah kontraktur dan meningkatkan fungsi motoriknya secara mandiri. Latihan pergerakan mandiri pasien menggunakan sisi anggota gerak yang tidak sakit untuk membantu menguatkan otot yang lemah dengan berbagai metode stimulasi salah satunya adalah dengan penyikatan. Penelitian ini bertujuan mengetahui pengaruh penggunaan sikat sensori terhadap kekuatan otot ekstremitas pada pasien stroke iskemik dengan hemiparesis. Metode penelitian adalah studi kasus menggunakan consecutive sampling. Dari hasil analisa didapatkan ada pengaruh penggunaan sikat sensori terhadap peningkatan kekuatan otot ekstremitas pada pasien stroke iskemik. Kesimpulan diperoleh dari studi kasus ini ada pengaruh penggunaan sikat sensori, terlihat dari perbedaan kekuatan otot ekstremitas pasien stroke berada pada skala 3 meningkat pada skala 4.

Kata kunci: Sikat Sensori, Kekuatan Otot, Stroke

\section{PENDAHULUAN}

Stroke merupakan gangguan aliran darah arteri ke otak secara tiba-tiba yang mengakibatkan terjadinya kerusakan kognitif yang berlangsung lebih lama dari 24 jam atau gangguan fungsi pergerakan, perasaan, memori, perabaan dan bicara yang bersifat sementara atau menetap (Hickey, 2014; Swan, et.al 2016).

Stroke merupakan keadaan darurat medis dan untuk orang yang mengalami stroke, perbedaan antara keduanya pulih dan kecacatan atau kematian diukur dalam hitungan jam (Swan, et.al 2016). Kecemasan dapat menjadi komplikasi pra operasi dan menghasilkan efek negatif pada kesejahteraan pasien dan cenderung memengaruhi pemulihan pasca operasi (Molavi, Masoudi, Razavi, Aghajani, Azizi, Vaghefi, 2013).

Hemiparesis merupakan penyebab umum kecacatan yang sering terjadi setelah serangan stroke, memengaruhi $70-85 \%$ dari semua pasien pasca stroke. Tingkat kesembuhan pasien mengalami peningkatan fungsi motorik sangat bervariasi dan lebih dari $50 \%$ pasien akan mengalami gejala sisa (Rydwik, Eliasson, 
Akner, 2006; Hendricks, Limbeek, Geurts, Zwarts, 2002).

Menurut National Stroke Association (2017), penanganan hemiparesis adalah program rehabilitasi yang ditujukan untuk meningkatkan fungsi motorik dan meminimalkan terjadinya kontraktur. Rehabilitasi dan latihan dengan terapi fisik dapat memperbaiki mobilitas anggota badan sisi yang terkena dampak secara perlahan. Aktivitas dan latihan teratur dengan pengulangan dapat memperbaiki kontrol pada anggota tubuh seseorang dengan hemiparesis. Hal ini juga dapat membangun kembali koneksi saraf.

Adanya sejumlah penelitian yang menunjukkan bahwa jika anggota badan sulit bergerak, maka stimulasi klinis dan relaksasi otot membantu membuat mereka bergerak dengan mudah. Perawatan rehabilitasi dapat dilakukan di rumah untuk pemulihan setelah terapi rawat inap secara singkat dan berulang sehingga aktivitas rutin dapat membantu meningkatkan kontrol dan fleksibilitas membangun kembali sirkuit saraf (National Stroke Association, 2017).

Kecepatan proses pemulihan motorik tergantung pada ketersediaan pesan sensorik yang dilakukan oleh aktifitas motorik. Beragam stimulus sensori dapat diberikan untuk memberi makna dan kesan kejadian yang telah terjadi pada lingkungan mereka yang mengalami penurunan sensitifitas neuronal.

Mekanisme umum dalam sistem sensorik (visual, pendengaran, penciuman dan somatosensori), yang merupakan rangsangan spesifik sangat bergantung pada kekuatan dan frekuensi stimulus. Dengan demikian, saat ini telah banyak diteliti dan dikembangkan perangkat atau teknik stimulasi otak noninvasif terhadap adaptasi monitor dalam sistem sensor yang dapat digunakan baik sebagai alat diagnostik maupun perawatan pasien. (Vries \& Mulder, 2007; Johansson, 2012).

Secara tradisional, terdapat empat penerapan stimulasi somatosensori yang dapat dibedakan kaitannya dengan gerak motorik yaitu: sentuhan, tekanan, suhu, dan getaran yang telah diakui sebagai pilihan terapi yang bermanfaat untuk perbaikan fungsional hemiparesis post stroke. Metode stimulasi melibatkan hubungan antara somatik, otonom dan psikologis yang bertujuan untuk memperbaiki pola normal gerakan secara aktif dan respon postural yang lebih baik. Berkaitan dengan hal itu menarik diketahui apakah masing-masing stimulus yang diberikan memainkan peran secara signifikan dalam proses belajar untuk mengembalikan fungsi motorik. (Sim, et al, 2015).

Stimulasi teknik sentuhan yang dikembangkan oleh Rood, (1950) salah satunya adalah Brushing atau penyikatan. Dahulu penyikatan dilakukan dengan menggunakan sikat yang dioperasikan dengan baterai, diletakkan pada kulit yang berada di atas otot untuk memudahkan terjadinya kontraksi otot. Penyikatan telah digunakan secara luas oleh ahli fisioterapi, diterapkan dengan menggunakan sikat yang dioperasikan secara elektrik atau secara manual menggunakan sikat botol, namun hanya sedikit yang membahas mengenai durasi penyikatan, atau tekanan yang dibutuhkan.

Garland dan Hayes (1987) mengamati efek peningkatan kekuatan kaki pasien hemiplegia, bahwa sedikit bukti untuk mendukung keefektifan dari teknik penyikatan pada pasien yang tidak dilakukan kombinasi pergerakan, sedangkan pada pasien yang diberikan kombinasi terjadi perubahan aktivitas elektromiografi (EMG) yang signifikan terlihat baik sesaat dan 30 menit setelah stimulasi. Hal ini dikarenakan stimulasi sensorik pada kulit telapak kaki yang telah dilakukan pergerakan terlebih dahulu dapat menstimulasi respon motorik untuk melakukan pergerakan normal. (Edmans, 2010).

Pada pengamatan gerakan, penyikatan daerah ekstremitas bagian bawah kaki bisa merangsang proprioseptor di telapak kaki untuk meningkatkan jumlah 
informasi aferen melalui sel tanduk anterior dan lingkaran gamma sehingga meningkatkan aktifitas otot yang melibatkan unsur kontraktil dan nonkontraktil otot (Page, et al 2010).

Beberapa studi telah menggunakan teknik penyikatan diantaranya Conforto, et al (2002), yang mengusulkan dari hasil penelitiannya tentang stimulasi somatosensori terhadap peningkatan kekuatan otot tangan penderita stroke. Bahwa keterlibatan somatosensori dalam bentuk stimulasi saraf perifer dapat mempengaruhi ukuran fungsional kinerja motorik.

Mereka mempelajari efek 2 jam stimulasi saraf median pada kekuatan otot pinch (sebuah fungsi yang dimediasi terutama oleh otot saraf medial saraf) di tangan penderita stroke yang mengalami cedera. Hasil ini menunjukkan bahwa stimulasi somatosensori dapat menjadi rehabilitasi defisit motorik pada pasien stroke.

Sim, et al (2015) mengetahui dampak langsung dari 4 jenis stimulasi somatosensori pada kekuatan fungsi tangan pasien hemiparesis post stroke, yaitu tidak ada stimulasi, vibrasi, sentuhan lembut dan sentuhan kasar menggunakan metode sikat, dilakukan secara acak pada sebelas pasien selama 4 hari yang masing-masing setiap harinya hanya menerapkan satu jenis stimulasi somatosensor. Bahwa terdapat perbedaan yang signifikan terhadap kekuatan fungsi dan pegangan tangan pasien pada vibrasi dan stimulasi sentuhan menggunakan sikat memiliki skor lebih tinggi daripada tidak diberikan stimulasi.

Brasil, et al (2008) menggunakan Moving Touch-Pressure Test (MTP), menguji sensorik pada pasien hemiparesis. Kedua tangan pasien dibandingkan sensitifitas dan pergerakannya baik tangan yang sehat maupun yang lemah menggunakan tiga jenis sikat yang berbeda ukuran, tekstur bulu pada sikat dan teknik penyikatan. Terjadi interaksi kompleks antara somatosensori daerah kedua belahan otak responden, ditandai adanya peningkatan yang signifikan dalam ketajaman spasial taktis dari tangan yang sehat.

Proses pemulihan tidak hanya memperbaiki fungsi saraf otak, namun juga bagaimana memampukan pasien dalam kegiatan aktifitas fungsional sehari-hari. Mekanisme yang mendasari hal ini, adalah pulihnya fungsi otak pada area penumbra yang berada disekitar area infark, sehingga kemampuan fungsional pulih sejalan dengan pemulihan neurologis yang terjadi. Metode terapi yang baik adalah melibatkan pasien sejak awal secara aktif semampunya, untuk mencegah komplikasi sekunder dan mengembalikan kemandirian pasien, sekaligus melibatkan dukungan keluarga sehingga dapat meringankan beban psikososial dan ekonomi pasien dan keluarga (Wirawan, 2009).

Pada studi pendahuluan yang dilakukan peneliti di RSUD Arifin Achmad Pekanbaru didapatkan bahwa penanganan pasien stroke yang mengalami hemiparesis yang dilakukan perawat dan fisioterapi adalah latihan pergerakan range of motion (ROM) setiap hari lebih kurang 15 menit dan belum memberikan perhatian khusus untuk melakukan latihan ROM kombinasi menggunakan teknik stimulasi dengan penyikatan sensorik pada pasien, sebagai bagian dari tindakan rehabilitasi keperawatan.

Penerapan sikat sensorik sebagai stimulasi sensorik ini dapat dikombinasikan sebelum latihan ROM dilakukan melalui serangkaian gerakan lembut dan sedikit tekanan, dengan melibatkan rangsangan taktil pada kulit ekstremitas atas dan bawah, menggunakan alat berbentuk sikat.

Hingga saat ini, masih terbatas penelitian di bidang keperawatan yang mengkhususkan penggunaan sikat sensorik pada pasien stroke iskemik untuk memperbaiki fungsi motorik dan kekuatan otot. Hal inilah yang melatarbelakangi peneliti untuk melakukan studi kasus tentang pengaruh sikat sensorik pada pasien stroke iskemik terhadap kekuatan otot ekstremitas dalam konteks asuhan keperawatan, sehingga dapat lebih menyempurnakan pelayanan keperawatan 
yang ada saat ini.

\section{METODE PENELITIAN}

Penelitian menggunakan metode deskriptif dengan pendekatan studi kasus yaitu perlakuan dan observasi pada pasien stroke iskemik hemiparesis, kekuatan otot 1-3, kesadaran komposmentis, tanda-tanda vital (tekanan darah, nadi, suhu dan pernapasan) pasien stabil dan dirawat di ruang Medikal RSUD Arifin Achmad Pekanbaru.

Pengumpulan data pasien dengan melihat catatan integrasi pasien, observasi dan wawancara dengan pasien dan keluarga. Pasien yang mendapat perlakuan tambahan berupa penggunaan sikat sensori dalam latihan ROM setiap 2 jam sekali yang dilakukan oleh perawat, adalah pasien yang telah direncanakan asuhan keperawatan terhadap gangguan mobilitas fisik yang terjadi akibat adanya lesi otak pada area motor korteks.

\section{HASIL DAN PEMBAHASAN Pengkajian}

Asuhan keperawatan pada Tn. T.R dengan stroke iskemik, dimulai dari pengkajian sejak tanggal 14 Desember 2020 jam 14.00 pasca rawat PINERE. Pasien rawat di PINERE dengan diagnosa Suspect COVID-19, namun setelah 3 hari rawat, hasil spesimen swab nasooroparing 1 dan 2 dinyatakan negatif. Pengkajian keperawatan dilakukan di ruang rawat inap RSUD Arifin Achmad Pekanbaru dengan keluhan utama ekstremitas kiri atas lemah dan tidak memiliki riwayat rawat stroke sebelumnya. Keadaan umum lemah, kesadaran komposmentis, tekanan darah 146/81 $\mathrm{mmHg}$, frekuensi nadi $84 \mathrm{kali} / \mathrm{menit}$, frekuensi napas $20 \mathrm{kali} / \mathrm{menit}$, suhu $36^{\circ} \mathrm{C}, \mathrm{SpO}_{2} 99 \%$.

Hasil pemeriksaan kekuatan otot pasien, didapatkan penurunan kekuatan dengan nilai 3, yaitu dapat mengadakan gerakan melawan gaya berat (gravitasi). Hasil pemeriksaan penunjang CTScan tanggal 11 Desember 2020, menunjukkan tidak terdapat perdarahan, diberikan terapi infus $\mathrm{NaCl}$ 0,9\% 20 tpm, oksigen nasal kanul 4 liter/menit, injeksi citicolin $2 \times 500 \mathrm{mg}$, injeksi lantus $1 \times 15$ unit, injeksi novorapid $3 \times 8$ unit, CPG $1 \times 75 \mathrm{mg}$, Aspilet 1x1, Azitromisin 1x500 mg.
Karakteristik jenis stroke iskemik pada pasien, jika dikaitkan dengan kejadian hemiparesis, bahwa pasien dengan stroke iskemik lebih tinggi dibandingkan dengan hemoragik. Sedangkan dengan kejadian kematian, berbanding terbalik, bahwa hemoragik lebih tinggi menyebabkan kematian dibanding iskemik (AHA, 2017). Karakteristik frekuensi stroke pertama kali pada pasien, menandakan adanya kerusakan sistem persarafan yang lebih kecil dibandingkan dengan orang yang dengan serangan stroke berulang. Begitupun terhadap masa pemulihan, bahwa serangan stroke berulang membutuhkan waktu dan latihan lebih lama (Damush, Plue, Bakas, Schmid, \& Williams, 2007).

Dari riwayat penyakit terdahulu pasien memiliki DM tipe II, hipertensi dan penyakit jantung sejak tahun 2019. Pada pemeriksaan tekanan darah didapatkan hasil melebihi batas normal yaitu 146/81 $\mathrm{mmHg}$. Diabetes melitus menjadi faktor resiko pada pasien ini untuk menderita stroke iskemik, karena dapat menyebabkan perubahan pada sistem vaskuler dan menstimulasi terjadinya aterosklerosis. Tekanan darah yang meningkat dapat menyebabkan pecahnya pembuluh darah ataupun secara perlahan merusak dinding pembuluh darah dengan memperkeras arteri dan mendorong adanya bekuan darah. Riwayat hipertensi lama, berpotensi menimbulkan serangan stroke akibat menyempitnya pembuluh darah otak yang mengganggu (Ignatavicius \& Workman, 2010).

\section{Diagnosa Keperawatan}

Masalah keperawatan yang dapat ditemukan pada pasien, yaitu gangguan mobilitas fisik berhubungan dengan lesi otak pada area motor korteks. Dari riwayat penyakit terdahulu pasien memiliki DM tipe II, hipertensi dan penyakit jantung sejak tahun 2019. Pada pemeriksaan tekanan darah didapatkan hasil melebihi batas normal yaitu 146/81 mmHg. didukung oleh hasil pemeriksaan kekuatan otot pasien, didapatkan penurunan kekuatan dengan nilai 3, yaitu dapat mengadakan gerakan melawan gaya berat (gravitasi). 


\section{Rencana Keperawatan}

Sehubungan dengan diagnosa medis dan masalah keperawatan yang ditegakkan, penulis menitikberatkan perencanaan inovasi perubahan pada masalah mobilitas fisik yang sangat besar mungkin terganggu. Salah satu masalah terkait kehilangan kontrol volunter terhadap gerakan motorik, pada salah satu sisi tubuh dapat menunjukkan adanya kerusakan pada neuron motor atas pada sisi yang berlawanan dari otak. Paling umum terjadi pada disfungsi motorik ini adalah hemiparesis (Smeltzer \& Bare, 2009).

Upaya rehabilitasi stimulus yang dilakukan adalah untuk meningkatkan fungsi motorik setelah terjadinya stroke. Pemulihan fungsional dikaitkan dengan proses reorganisasi di otak yang rusak. Reorganisasi dalam sistem (self-organisasi) bisa terjadi bila kerusakan fungsional sistem parsial, namun bila sistem fungsional benar-benar rusak, pemulihan sebagian besar dicapai dengan proses substitusi, dimana ketika salah satu sistem fungsional otak terganggu, maka daerah otak yang lain akan mengambil alih fungsi daerah yang terganggu. (Vries \& Mulder, 2007)

Intervensi yang dilakukan adalah latihan ROM pasif maupun aktif di tempat tidur, kemudian dilakukan penilaian fungsi motorik secara teratur. Untuk meningkatkan fungsi motorik dan kekuatan otot, dapat dilakukan penggunaan sikat sensori oleh tangan pasien yang sehat ke tangan yang lemah sebelum dilakukan ROM oleh perawat. Diharapkan dengan perawatan dan latihan ROM ditambah stimulasi penyikatan sensorik pada pasien, dapat memudahkan terjadinya kontraksi otot dengan meningkatkan kenyamanan pasien dan nilai kekuatan otot meningkat sehingga mempercepat pemulihan.

Stimulasi sikat sensori berdasarkan pada respon fisiologis merupakan dukungan mobilisasi dan ambulasi pada gangguan mobilitas fisik. Latihan pergerakan mandiri oleh pasien menggunakan sisi anggota gerak yang tidak sakit bertujuan membantu menguatkan otot anggota gerak yang lemah dengan berbagai media stimulasi salah satunya adalah dengan metode penyikatan

\section{Implementasi Keperawatan}

Pada pasien stroke iskemik dengan gangguan mobilitas fisik, setelah diberikan tindakan mandiri keperawatan yaitu perlakuan ROM menggunakan penambahan stimulasi menggunakan sikat sensori setiap 2 jam sekali (2-3 menit) dalam satu kali penyikatan selama 4 hari (14-18 Desember 2020), terlihat bahwa pasien merasa lebih santai, bersemangat dan nyaman karena dapat melakukan ROM aktif secara minimal menggunakan sikat sensori sebelum ROM dilakukan. Hasil tindakan sebagai berikut:

Pada tanggal 18 Desember 2020 jam 17.00 sebelum dilakukan ROM dengan penambahan stimulasi sikat sensori, nilai pengukuran kekuatan otot 3, setelah dilakukan ROM dengan penambahan stimulasi sikat sensori, nilai pengukuran kekuatan otot sudah pada rentang 4 .

\section{Tabel 1.}

Perubahan kekuatan otot sebelum dan sesudah dilakukan ROM dengan penambahan stimulasi sikat sensori setiap 2 jam sekali selama 4 hari

\begin{tabular}{|c|c|c|}
\hline $\begin{array}{c}\text { Hari } \\
\text { ke- }\end{array}$ & $\begin{array}{l}\text { Nilai } \\
\text { Kekuatan } \\
\text { Otot }\end{array}$ & Waktu \\
\hline 1 & 3 & $\begin{array}{c}2-3 \text { menit Sensori }+15 \\
\text { menit ROM }\end{array}$ \\
\hline 2 & 3 & $\begin{array}{c}2-3 \text { menit Sensori }+15 \\
\text { menit ROM }\end{array}$ \\
\hline 3 & 3 & $\begin{array}{c}2-3 \text { menit Sensori }+15 \\
\text { menit ROM }\end{array}$ \\
\hline 4 & 4 & $\begin{array}{c}2-3 \text { menit Sensori }+15 \\
\text { menit ROM }\end{array}$ \\
\hline
\end{tabular}

Tabel 1 menunjukkan bahwa pasien dilakukan tindakan ROM selama 15 menit dengan penambahan stimulasi sikat sensori 2-3 menit sebelum ROM dilakukan, pada hari ke-4 terjadi peningkatan kekuatan otot dari skala 3 menjadi 4.

\section{Evaluasi Keperawatan}

Setelah diberikan intervensi inovasi stimulasi sikat sensori 2-3 menit dan ROM 
selama 15 menit pada Tn. T.R, tekanan darah 136/79 $\mathrm{mmHg}$, frekuensi nadi $82 \mathrm{kali} /$ menit, frekuensi napas $20 \mathrm{kali} / \mathrm{menit}$, suhu $36^{\circ} \mathrm{C}$, $\mathrm{SpO}_{2} 99 \%$. Pemberian stimulasi sikat sensori yang dikombinasikan sebelum latihan ROM melalui serangkaian gerakan lembut dan sedikit tekanan melibatkan rangsangan taktil pada kulit ekstremitas atas dan bawah dengan menggunakan alat berbentuk sikat.

Penatalaksanaan non farmakologi gangguan mobilitas fisik berhubungan dengan lesi otak pada area motor korteks pada pasien stroke iskemik, dapat dilakukan dengan terapi latihan motorik secara aktif dan pasif. Latihan bertujuan untuk mempercepat proses pemulihan selain memperbaiki fungsi saraf otak melalui terapi farmakologi, namun juga bagaimana memampukan pasien secara mandiri dalam kegiatan fungsional sehari-hari. Rasional tindakan mandiri keperawatan yang dilakukan berdasarkan bahwa tingkat pemulihan pasien hanya bergantung pada tingkat cedera di otak. Hemiparesis dengan kelumpuhan parsial bisa dipulihkan sebanyak $70 \%$ dengan kemampuan fungsional tangan mereka melalui terapi fisik maupun terapi fisik alternatif. Pada pasien stroke iskemik yang mengalami hemiparesis pemilihan rehabilitasi yang tepat dengan terapi fisik meningkatkan peluang pemulihan (National Stroke Association, 2017).

Berdasarkan analisa dan pembahasan mengenai masalah mobilitas fisik terhadap pemberian stimulasi sikat sensori sebelum ROM dilakukan bertujuan meningkatkan mobilitas, kekuatan dan penggunaan ekstremitas yang lemah. Intervensi yang dilakukan pada pasien dengan gangguan mobilisasi sesuai dengan NIC (Nursing Intervention Classification) diantaranya adalah terapi aktifitas, tehnik distraksi, pencegahan jatuh, perawatan kaki, manajemen terapi, manajemen nyeri, monitor status neurologi, manajemen saraf tepi, manajemen daerah tubuh yang tertekan, masase sederhana, manajemen integritas kulit, dan manajemen berat badan, (Moorhead, 2007). Stimulasi sikat sensori merupakan intervensi mandiri keperawatan yang didalamnya terdapat perlakuan terapi aktifitas fisik, teknik distraksi, manajemen saraf tepi dan massase sederhana. Sikat sensori menggunakan teknik penyikatan terapeutik teknik Deep Pressure Protocol yaitu protokol yang sangat spesifik, memerlukan lebih dari sekadar menyikat kulit. Wilbarger (1995), mengatakan bahwa perawatan yang dipandu secara profesional ini terdiri dari penggunaan sikat khusus yang lembut atau menggunakan sikat bedah yang khas atau sikat jenis lainnya. Stimulus sensori mencapai organ sensori dan menghasilkan reaksi yang segera, kemudian disimpan ke otak untuk digunakan dimasa depan dalam menerima persepsi stimulus untuk diinterpretasikan.

Perawatan ini hampir tidak ada risiko atau efek samping negatif. Prosedur ini dilakukan selama 2-3 menit dan diulang setiap dua jam di siang hari atau setiap dua jam sekali perubahan posisi di tempat tidur karena telah dibuktikan bahwa efek rangsangan berlangsung sekitar itu. Efek dari perawatan ini adalah menenangkan dan mengatur kembalinya aktivitas motorik melalui rangsangan sensori ke dalam rutinitas sehari-hari pasien (Karen \& Henry, 2015., Therakids, 2013)

Tindakan keperawatan dapat membantu pasien untuk mendapatkan kembali kekuatan otot-otot. Tindakan rehabilitasi ROM memungkinkan pasien dapat beradaptasi secara fisik dengan keadaannya (Smeltzer \& Bare, 2009). Dengan menjalani rehabilitasi secara rutin diharapkan pasien dapat memiliki kekuatan otot penuh di kedua sisi tubuh mereka.

\section{SIMPULAN}

Perbedaan kekuatan otot ekstremitas pada pasien stroke iskemik yang mengalami gangguan mobilitas fisik sebelum perlakuan, berada pada skala 3 dan setelah perlakuan pada hari pertama sampai keempat, meningkat pada skala 4 yaitu disamping dapat melawan gaya berat (gravitasi), pasien dapat pula mengatasi sedikit tahanan yang diberikan.

Setelah dilakukan ROM dengan stimulasi sikat sensori hasil observasi menunjukkan bahwa terdapat perubahan yang signifikan terhadap peningkatan 
kekuatan otot ekstremitas pasien, dimana latihan yang dilakukan setiap 2 jam sekali selama 4 hari, menstimulus impuls otak melalui otot tak sadar dan saraf sensorik untuk kontraksi dan memperkuat bagian yang lemah, melalui gerak stimulus neuromuskular yang benar sehingga mempermudah timbulnya reaksi atau gerakan.

\section{DAFTAR PUSTAKA}

American Heart Association/American Stroke Association (AHA/ASA). (2017). Heart Disease and Stroke Statistic-2017 update. Retrieved from: http://circ.ahajournals.org doi: 10.1161/CIR.0000000000000485

Astrid, M. (2008). Tesis: Pengaruh latihan range of motion (ROM) terhadap kekuatan otot, luas gerak sendi dan kemampuan fungsional pasien stroke di RS Sint Carolus Jakarta. Depok: Program Studi Pasca Sarjana FIK UI. Tidak dipublikasikan.

Black, J. M., \& Hawk, J. H. (2014). Medical Surgical Nursing, Clinical Management for Continuity of Care. $^{\text {th }}$ ed. JB. Lipincott.co.

Brasil, N., Joaquim, P., Lima, A.C. (2008). Sensory deficits in the unaffected hand of hemiparetic stroke patients. Cogbehavneurol. Volume 21, Number 4, Dcember 2008; 202-205. Retrieved from: http://www.journals.lww.com doi: 10.1097/WNN.0b013e3181864a24

Champagne, T. (2006). Sensory Modulation and Environment: Essential Elements of Occupation (2nd Ed). Southampton, MA: Champagne Conferences \& Consultation.

Conforto, A.B., Kaelin, L., Cohen, L.G. (2002). Increase in hand muscle strength of stroke patients after somatosensory stimulation. Annals of Neurology. Vol.51, isue 1, 2002, pages 122-125. Retrieve from: The Society of Physical Therapy Science, 27(5), 1445-1449. Retrieved from http://www.elsevier.com DOI: 10.1002/ana.10070

Damush, T.M., Plue, L., Bakas, T., Schmid, A., \& Williams, L.S. (2007). Barriers and facilitators to exercise among stroke survivors. Rehabilitation Nursing, 32 (6),
253-60, 262.

Dharma, K. K. (2011). Metodologi Penelitian Keperawatan: Panduan Melaksanakan dan Menerapkan Hasil Penelitian. Jakarta: Trans Info Media.

Edmans, J. (2010). Occupational therapy and stroke. Second edition. WileyBlackwell. A John Wiley \& Sons, Ltd, Publication.

Hastono, S. P. (2007). Basic Data Analysis For Health Research Training: Analisis Data Kesehatan. Depok: FKM Universitas Indonesia.

Hendricks, H.T., Limbeek, V., Geurts, A.C., Zwarts, M.J. (2002). Motor recovery after stroke: a systematic review of the literature. Upload by Geurts 23 Januari 2015, Retrieved from:

https://www.researchgate.net/publicati on/11044575.

DOI:

10.1053/apmr.2002.35473. Source:

PubMed

Ignatavicius, D.D \& Workman, M.L. (2010). Medical Surgical Nursing: Patient Centered Collaborative Care. Sixth Edition. USA: Elseiver.

Johansson, B.B. (2012). Multisensory stimulation in stroke rehabilitation. Frontiers in Human Neuroscience. Departement of Clinical Neuroscience, Wallenberg Neuroscience center, Lund, Sweden. Retrieved from: http://www.Frontiersin.org doi: 10.3389/fnhum.2012.00060

Karen, M., M \& Henry, A.D. (2008). Treatment of Adult Psychiatric Patients Using the Wilbarger Protocol. Retrieved from: http://dx.doi.org/10.1300/J004v18n01_ $\underline{03}$

Kementrian Kesehatan Republik Indonesia. (14 Juli 2014). Riset Kesehatan Dasar Kemenkes. Diperoleh tanggal 9 Mei 2017

dari http://www.depkes.go.id/Hasil\%20Risk esdas\%202013.pdf

Lumbantobing, S.M. (2008). Neurologi klinik: Pemeriksaan fisik dan mental. Cetakan ke-11. Jakarta: Balai Penerbit 
FKUI.

Moorhead, S., et al (2007), Nursing intervention classification (NIC). 4 th edition. St. Louis Missouri: Elsevier Saunders.

Moorhead, S., et al (2007), Nursing outcomes classification (NOC). 4 th edition. St. Louis Missouri: Elsevier Saunders.

National Stroke Association (NSA). (2017). Hemiparesis. Diperoleh tanggal $11 \mathrm{Mei}$ 2017 dari http://www.stroke.org/

Notoatmodjo, S. (2010). Metodologi Penelitian Kesehatan. Jakarta: Rineka Cipta.

Page, P., Frank, C.C., Lardner, R. (2010). Assessment and treatment of muscle imbalance: the Janda approach. Benchmark Physical Therapy Inc.

Polit, D.F., \& Hungler, B.P. (2010). Nursing Research: Principles \& Methods. Ed 6. Philadelphia: Lippicott Williams \& Wilkins.

Pouydebatet, E., Fragaszy, D., Kivel, T.L. (2014). Grasping in primates: for feeding, moving and human specificities. BMSAP. October 2014, Volume 26, isuue 3, pp 129-133. Retrieved from: http://www.link.springer.com/journal/132 19/26/3/ DOI: 10.1007/s13219-014-01007

Prince, S.A \& Wilson, L.M. (2006). Patofisiologi: Konsep Klinis Prosesproses Penyakit. Jakarta: EGC.

RNAO Nursing Best Practice Guidelines Program. (2005). Stroke assessment across the continuum of care. Nursing Best Practice Guideline. Shaping the future of Nursing. Nurses Association of Ontario.

Rydwik, E., Eliasson, S and Akner, G. (2006). The effect of exercise of the affected foot in stroke patients - a randomized controlled pilot trial. Nutrition and Pharmacotherapy Unit, Research and Development Unit for the Elderly North West, Karolinska Institute, Jakobsbergs Hospital, Sweden. Retrieved from: http://www.cre.sagepub.com DOI:10.1191/0269215506cre986oa

Sastroasmoro, S., \& Ismael, S. (2010). Dasar- dasar metodologi penelitian klinis. Edisi ke-3. Jakarta: CV Sagung Seto.

Sim, S.M., Oh, D.W., Chon, S.C. (2015). Immediate effects of somatosensory stimulation on hand function in patients with poststroke hemiparesis: a randomized cross-over trial. International Journal of Rehabilitation Research: December 2015 - volume 38-issue 4 - p 306-312. DOI: 10.1097/MRR.0000000000000126

Smeltzer, S.C., \& Bare. B.G., (2009). Texbook of medikal surgical nursing. $11^{\text {th }}$ Ed. Philladelphia: Lipincott Williams \& Wilknis.

Swan, J., Jouria, J.M., Katz, M.J. (2016). Stroke: Comprehensive acute stroke care. Retrieved from http://www. wildirismedicaleducation.com

Teitelbaum, J.S., Eliasziw, M., \& Garner, M. (2002). Tests of motor function in patients suspected of having mild unilateral cerebral lesions. The Canadian Journal of Neurological Sciences 2002 Nov;29(4):337-344. PubMed PMID: 12463489. http://www.ncbi.nlm.nih.gov/pubmed/ 12463489

Therakids. (2013). Wilbarger deep pressure protocol. Newsletters. September, 2013. Retrieved from: http://www.therakids.org

The Wilbarger Protocol (Brushing Therapy) for Sensory Integration https://www.thehealthhub.org.au/thewilbarger-protocol-brushing-therapyfor-sensory-integration

Vries, S.D \& Mulder, T. (2007). Motor imagery and stroke rehabilitation: critical discussion. Journal Rehabilitation Medical 2007; 39: 5-13. DOI:10.2340/16501977-0020

Warlow, C. et al. (2007). Stroke: Practical management. 5th ed. Blackwell Publishing, Inc.,350 Main Street, Malden, Massachusetts 02148-5020, USA.

Wirawan, R.P. (2009). Rehabilitasi stroke pada pelayanan kesehatan primer. Majalah Kedokteran Indonesia, 
Volume 59, Nomor 2, Pebruari 2009.

Diperoleh tanggal 10 Mei 2017, dari http://www.indonesia.digitaljournals.org

Wibowo, A. (2014). Metodologi Penelitian

Praktis Bidang Kesehatan. Jakarta: PT RajaGrafindo Persada.

Wilbarger, J. \& Wilbarger, P. (2002).

Wilbarger approach to treating sensory defensiveness and clinical application of the sensory diet. Sections in alternative and complementary programs for intervention, In Bundy, A.C., Murray, E.A., \& Lane, S. (Eds.). Sensory Integration: Theory and Practice, 2nd Ed. F.A. Davis, Philadelphia, PA. 